УДК 615.1:614.27:164.08:614.253.8

DOI https://doi.org/10.11603/2312-0967.2021.1.11937

\title{
КОНЦЕПТУАЛЬНЕ МОДЕЛЮВАННЯ ЯКОСТІ ФАРМАЦЕВТИЧНОЇ ДОПОМОГИ З ПОЗИЦІЙ Ї̈ ТЕРМІНОСТРУКТУРНИХ ЕЛЕМЕНТІВ ТА ВЗАЄМОЗВ'ЯЗКУ З ЛОГІСТИЧНИМ ОБСЛУГОВУВАННЯМ ПАЦІЄНТА
}

\author{
М. В. Корольов \\ Одеський національний медичний університет \\ Marat.korolev@gmail.com
}

ІНФОРМАЦІЯ

Надійшла до редакції / Received: 13.01.2021

Після доопрацювання / Revised: 18.01.2021

Прийнято до друку / Accepted: 22.01.2021

\section{Ключові слова:}

фармацевтична допомога; якість;

терміноструктурні елементи; логістичне обслуговування; взаємозв'язок; моделювання.

\begin{abstract}
АНОТАЦІЯ
Мета роботи. Опрацювання концептуальної моделі взаємозв'язку основних характеристик якості фрармацевтичної допомоги з їі терміноструктурними елементами та складовими логістичного обслуговування пацієнта.

Матеріали і методи. Матеріалом дослідження були теоретичні питання фрармацевтичної допомоги та логістичного обслуговування пацієнта. Використано методи наукового узагальнення та моделювання.

Результати й обговорення. На основі узагальнення вербального опису прикмет дев'яти характеристик якості фрармацевтичної допомоги (належний терапевтичний конкорданс, пацієнт-орієнтованість результатів, доступність, раціональність, ефрективність, безпечність, своєчасність, відсутність (мінімізація) лікопов'язаних помилок і неперервність), її чотирьох терміноструктурних елементів (надавачі й отримувачі, предмет і очікуваний результат) та семи складових логістичного обслуговування пацієнта (необхідному пацієнту необхідні лікарські засоби необхідної дози необхідної якості необхідної вартості у необхідному місці та в необхідний час) здійснено їхню структуризацію та визначено особливості взаємозв'язку у вигляді концептуальної моделі. Важливість опрацьованої концептуальної моделі полягає передусім у тому, що вона уможливлює наочну оцінку рівня фармацевтичної допомоги з позиції ії̈ багатоаспектності та дає можливість прийняти раціональні управлінські рішення щодо покращення якості орармацевтичної допомоги.

Висновки. Здійснено концептуальне моделювання і наукове обґрунтування теоретичних засад взаємозв'язку якості фрармацевтичної допомоги 3 ії терміноструктурними елементами та складовими логістичного обслуговування пацієнта.
\end{abstract}

Вступ. Для аптечної служби як складової фрармацевтичного сектора охорони здоров'я за останні десятиліття потужним стимулом подальшого розвитку стало активне застосування концепцій фрармацевтичної допомоги (ФД) та логістичного обслуговування пацієнта (ЛОП).

У сучасному розумінні ФД - це фрілосоорія фрармацевтичної практики, яка полягає у піклуванні фрарма- цевтичного фрахівця (ФФ) у взаємодії з лікарем над особами (хворим, їхніми родичами й близькими) впродовж усього періоду індивідуалізованої фрармакотерапії за заздалегідь опрацьованим планом з метою запобігання лікопов'язаним проблемам та їхній корекції, збереження або покращення якості життя. При цьому в терміноструктурі ФД присутні її чотири

ISSN 2312-0967. Pharmaceutical review. 2021. № 1 
Організація роботи аптечних підприємств

\section{Organization of pharmaceutical structures' work}

елементи - надавачі й отримувачі, предмет і очікуваний результат [1]. Якість (Quality) ФД інтерпретується як сукупність її характеристик, які показують здатність ФД задовольняти потреби пацієнтів з урахуванням положень належної аптечної практики і протоколів провізора (фармацевта), що відповідають сучасному рівню фрармацевтичної науки. Виокремлюють дев'ять основних характеристик якості (9Q) ФД: належний терапевтичний конкорданс (Q1), пацієнт-орієнтованість результатів (Q2), доступність (Q3), раціональність (Q4), ефективність (Q5), безпечність (Q6), своєчасність (Q7), відсутність (мінімізація) лікопов'язаних помилок (Q8) [2] і неперервність (Q9) [3].

Щодо ЛОП, то це процес створення блага шляхом реалізації комплексу логістики (7R): необхідному пацієнту (R1) необхідні лікарські засоби - лз (R2) необхідної дози (R3) необхідної якості (R4) необхідної вартості (R5) у необхідному місці (R6) та в необхідний час (R7) [4].

Доречно зазначити, що були науково опрацьовані особливості взаємозв'язку лОП із концепціями ФД належної аптечної практики [5]. Теж був реалізований словесний опис взаємозв'язку ЛОП з якістю ФД [2]. Проте не здійснено концептуальне моделювання, яке б наочно поцінувало основні характеристики якості ФД із позицій ії надавача, отримувача, предмета й очікуваних результатів та взаємозв'язку 3 лоп.

Мета роботи: опрацювання концептуальної моделі взаємозв'язку основних характеристик якості ФД з її терміноструктурними елементами (TCE) та складовими ЛОП.

Матеріали і методи. Матеріалом дослідження були теоретичні питання ФД та ЛОП. Використано методи наукового узагальнення та моделювання.

Результати й обговорення. На основі узагальнення вербального опису прикмет якості ФД, її ТСЕ та складових ЛОП здійснено їхню структуризацію та визначено особливості взаємозв'язку у вигляді концептуальної моделі. 3 даних, наведених на рисунку, видно, що:

- належний терапевтичний конкорданс (Q1) формує предмет ФД - процес розробки взаємно узгодженого плану терапії за участю її суб'єктів (надавача та отримувача) - лікаря, хворого і ФФ; ця характеристика якості пов'язана з усіма складовими (7R) лОП;

- пацієнт-орієнтованість результатів (Q2), які можна здобути (як результат ФД) завдяки професійній здатності ФФ (надавача ФД) опікуватися хворим та його родичами й близькими (отримувачами ФД) способами, які є значущими, цінними та корисними для пацієнта, позаяк зосереджуються на його переконаннях, думках та потребах (предмет ФД); ця характеристика якості ФД пов'язана з усіма складовими (7R) ЛОП;
- доступність (Q3), яка характеризує предмет і результат ФД шляхом урегулювання нормативного та організаційного забезпечення можливості отримання кваліфікованої ФД; ця характеристика пов'язана з такими складовими ЛОП, як необхідні Л3 (R2) необхідної дози (R3) необхідної якості (R4) необхідної вартості (R5) у необхідному місці (R6);

- раціональність (Q4), яка фрормується поєднанням трьох ТСЕ ФД (отримувачів, предмета та результату) і розкриває надання пацієнтам ФД відповідно до клінічної необхідності та індивідуальних потреб хворого упродовж адекватного проміжку часу і при мінімальних витратах як самих пацієнтів, так і суспільства загалом; ця характеристика пов'язана зі складовими лОП - необхідної якості (R4) необхідної вартості (R5) у необхідний час (R7);

- ефективність (Q5), яка реалізується через предмет і результат ФД та показує відповідність фрактично наданої (при наявних ресурсах) ФД оптимальному для конкретних умов результату, визначеному національними стандартами 3 належної аптечної практики та іншими нормативними документами, а також нормами фрармацевтичної етики; ця характеристика якості ФД пов'язана зі складовою ЛОП - необхідної якості (R4);

- безпечність (Q6), яка здійснюється через три ТСЕ ФД (надавача, отримувача і результат) та забезпечує гарантії безпеки для життя і здоров'я пацієнта та відсутності шкідливих впливів на хворого і ФФ в конкретному закладі охорони здоров'я, зокрема в аптеці, $з$ урахуванням санітарно-епідеміологічної безпеки; ця характеристика якості ФД пов'язана зі складовою ЛОП - необхідної якості (R4);

- своєчасність (으), яка відбувається через отримувача, предмет і результат ФД шляхом її надання тоді, коли це необхідно пацієнтові, тобто у потрібний момент, доречно; ця характеристика якості пов'язана зі складовою ЛОП - у необхідний час (R7);

- відсутність (мінімізація) лікопов'язаних помилок (Q8), а саме будь-яких подій, які можна запобігти та які можуть спричинити або призвести до невідповідного вживання Лз або шкоди пацієнту (результат ФД), коли застосування ЛЗ (предмет ФД) контролюють лікар, ФФ, хворий, його родичі й близькі (надавачі й отримувачі ФД); ця характеристика якості ФД пов'язана зі складовими лОР - необхідному пацієнту (R1) необхідні Л3 (R2) необхідної дози (R3) необхідної якості (R4);

- неперервність (Q9), яка реалізується через усі TCE ФД та означає охоплення пацієнта ФД упродовж усього його життя та включає вибудовування і підтримання тривалих стосунків ФФ - пацієнт, управлінську (скоординованість ФД різних надавачів), інформаційну (доступність інформації про пацієнтів надавачам у всій системі охорони здоров'я) та реляційну (терапевтичні відносини між пацієнтом та одним або кіль-

ISSN 2312-0967. Фармацевтичний часопис. 2021. № 1 
Організація роботи аптечних підприємств

Organization of pharmaceutical structures' work

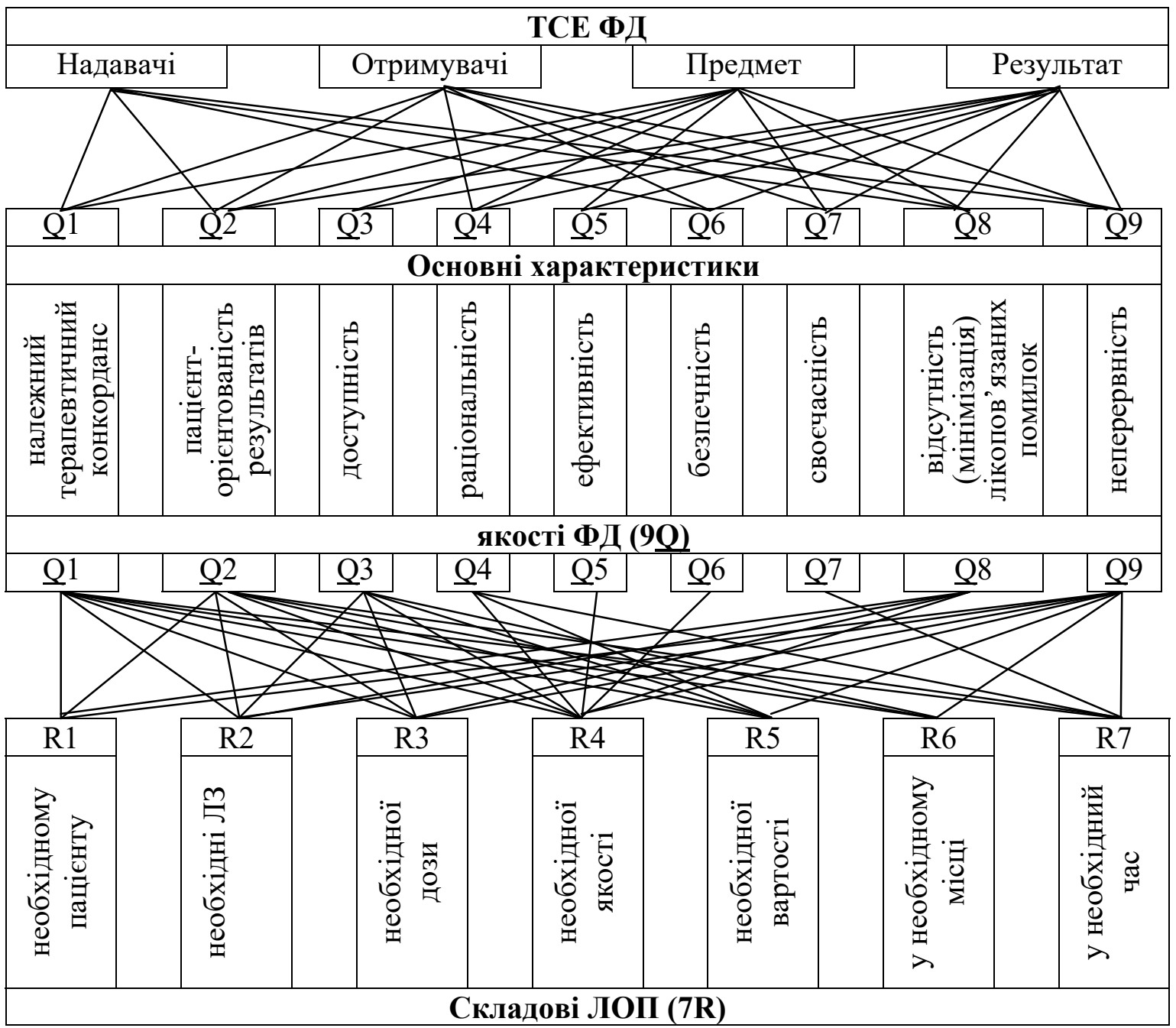

Рис. Концептуальна модель взаємозв'язку якості ФД з ї̈ ТСЕ і складовими ЛОП.

кома надавачами ФД, які охоплюють ФД у минулому, поточну та у майбутньому) неперервність; ця характеристика якості пов'язана з усіма складовими (7R) лОП.

Важливість опрацьованої концептуальної моделі полягає передусім у тому, що вона уможливлює наочну оцінку рівня ФД із позиції багатоаспектності, зокрема 3 погляду ТСЕ ФД і складових ЛОП, та дає можливість прийняти раціональні управлінські рішення щодо покращення якості ФД.

Висновки. Здійснено концептуальне моделювання і наукове обґрунтування теоретичних засад взаємозв'язку якості ФД з її ТСЕ і складовими лОП.

Конфлікт інтересів: відсутній.

Conflicts of interest: author has no conflict of interest to declare. 
Організація роботи аптечних підприємств

Organization of pharmaceutical structures' work

\title{
CONCEPTUAL MODELING OF THE QUALITY OF PHARMACEUTICAL CARE FROM THE POSITIONS OF ITS TERMINOLOGICAL STRUCTURE ELEMENTS AND OF INTERCONNECTION WITH PATIENTS' LOGISTICS SERVICES
}

\author{
M. V. Korolyov \\ Odesa National Medical University \\ Marat.korolev@gmail.com
}

The aim of the work. Development of a conceptual model of the relationship between the main characteristics of the quality of pharmaceutical care with its terminological structure elements and components of patients' logistics services. Materials and Methods. The theoretical issues of pharmaceutical care and patients' logistics services were the materials of the research. The methods of scientific generalization and modeling were used.

Results and Discussion. On the basis of the generalization of the verbal description of features of the nine characteristics of the quality of pharmaceutical care (good therapeutic concordance, patient-oriented results, availability, rationality, efficiency, safety, timeliness, absence (minimization) of drug-related errors and continuity), its four terminological structure elements (providers and recipients, subject and expected result) and seven components of patients' logistics services (the right patient, the right drug, the right dose, the right quality, the right price, the right place and at right time), their structuring was carried out and features of interrelation in the form of conceptual model were defined. The importance of the developed conceptual model is, first of all, that it allows a clear assessment of the level of pharmaceutical care from the standpoint of its multifaceted nature and allows rational management decisions to improve the quality of pharmaceutical care.

Conclusions. Conceptual modeling and scientific substantiation of the theoretical bases of interconnection of quality of pharmaceutical care with its terminological structure elements and components of patients' logistics services were carried out.

Key words: pharmaceutical care; quality; terminological structure elements; patients' logistics services; interconnection; modeling.

\section{КОНЦЕПТУАЛЬНОЕ МОДЕЛИРОВАНИЕ КАЧЕСТВА ФАРМАЦЕВТИЧЕСКОЙ ПОМОЩИ С ПОЗИЦИЙ ЕЕ ТЕРМИНОСТРУКТУРНЫХ ЭЛЕМЕНТОВ И ВЗАИМОСВЯЗИ С ЛОГИСТИЧЕСКИМ ОБСЛУЖИВАНИЕМ ПАЦИЕНТА}

\author{
М. В. Королев \\ Одесский национальный медицинский университет \\ Marat.korolev@gmail.com
}

Цель работы. Разработка концептуальной модели взаимосвязи основных характеристик качества фрармацевтической помощи с ее терминоструктурными элементами и составляющими логистического обслуживания пациента.

Материалы и методы. Материалом исследования были теоретические вопросы фрармацевтической помощи и логистического обслуживания пациента. Использованы методы научного обобщения и моделирования.

Результаты и обсуждение. На основе обобщения вербального описания примет девяти характеристик качества фрармацевтической помощи (надлежащий терапевтический конкорданс, пациент-ориентированность результатов, доступность, рациональность, эффрективность, безопасность, своевременность, отсутствие (минимизация) ошибок, связанных с лекарствами, и непрерывность), четырех ее терминоструктурных элементов (поставщиков и получателей, предмет и ожидаемый результат) и семи составляющих логистического обслуживания пациента (необходимому пациенту необходимые лекарства необходимой дозы необходимого качества необходимой стоимости в необходимом месте и в необходимое время) осуществлена их структуризация и определены особенности взаимосвязи в виде концептуальной модели. Важность разработанной концептуальной модели заключается, прежде всего, в том, что она делает наглядную оценку уровня фармацевтической помощи с позиции ее многоаспектности и позволяет принимать рациональные управленческие решения по улучшению качества фрармацевтической помощи.

Выводы. Осуществлено концептуальное моделирование и научное обоснование теоретических основ взаимосвязи качества фрармацевтической помощи с ее терминоструктурными элементами и составляющими логистического обслуживания пациента.

Ключевые слова: фрармацевтическая помощь; качество; терминоструктурные элементы; логистическое обслуживание пациента; взаимосвязь; моделирование.

ISSN 2312-0967. Фармацевтичний часопис. 2021. № 1 


\section{Список бібліографічних посилань}

1. Унгурян Л. М., Громовик Б. П., Горілик А. В. Термінологічна сутність фрармацевтичної допомоги. Одес. мед. журн. 2016. № 1. С. 38-44.

2. Громовик Б. П., Корольов М. В. Вербальне моделювання взаємозв'язку якості фрармацевтичної допомоги та логістичного обслуговування пацієнта. Актуальні проблеми розвитку галузевої економіки та логістики: матер. VIII наук. - практ. internet-конференції 3 міжнар. участю, Харків, 12 листопада 2020 р.; ред. кол. : О. В. Посилкіна, О. В. Літвінова, А. Г. Лісна. Харків : НФаУ, 2020. C. $48-49$.

\section{References}

1. Unhurian LM, Hromovyk BP, Horilyk AV. [Terminological essence of pharmaceutical care]. Odeskyi medychnyi zhurnal. 2016;1: 38-44. Ukrainian.

2. Hromovyk BP, Korolyov MV. [Verbal modeling of the relationship between the quality of pharmaceutical care and patients' logistics services]. Actual problems of industrial economy and logistics development: materials of VIII scientific and practical internet-conference with international participation. November 12, 2020; ed. board.: OV. Posilkina, OV. Litvinova, AG. Lisna. Kharkiv: NUPh, 2020;48-9. Ukrainian.

3. Wick Y. Jeannette. Broadening Pharmacy's
3. Wick Y. Jeannette. Broadening Pharmacy's Role: Continuity of Care. URL: https://www.pharmacytimes.com/ publications/issue/2006/2006-05/2006-05-5537.

4. Громовик Б. П. Особливості реалізації процесу логістичного обслуговування пацієнтів у системі фрармацевтичного обслуговування. Упр., екон. та забезп. якості в фрармації. 2011. № 3. С. 44-49.

5. Громовик Б. П., Унгурян Л. М. Наукове бачення взаємозв'язку логістичного обслуговування пацієнтів з концепціями фрармацевтичної допомоги і належної аптечної практики. Запорож. мед. журн. 2012. № 4. C. 81-84.

Role: Continuity of Care. Available from: https:// www.pharmacytimes.com/publications/issue/2006/2006-05/2006-05-5537.

4. Hromovyk BP. [Features of the realization of the process of patients' logistics services in the pharmaceutical service system]. Upravl, ekon ta zapez yak v farm. 2011;3: 44-9. Ukrainian.

5. Hromovyk BP, Unhurian LM. [Scientific vision of the relationship between patients' logistics care with the concepts of pharmaceutical care and good pharmacy practice]. Zaporizkyi medychnyi zhurnal. 2012;4: 81-4. Ukrainian.

\section{Відомості про автора}

Корольов М. В. - асистент кафедри загальної фармації з курсом клінічної фармакології, Одеський національний медичний університет, Одеса, Україна. Email: Marat.korolev@gmail.com, ORCID 0000-0001-7435-8265.

Information about the author

Korolyov M. V. - assistant of the Department of General Pharmacy with a Course of Clinical Pharmacology, Odesa National Medical University, Odesa, Ukraine. Email: Marat.korolev@gmail.com, ORCID 0000-0001-7435-8265. 